\title{
Serum apolipoprotein B increased among tuberculosis patients compared to healthy subjects
}

\author{
Augustine C. Ihim ${ }^{1 *}$, Samuel C. Meludu ${ }^{1,2}$, Charles C. Onyenekwe ${ }^{1}$, \\ Arthur E.Anyabolu ${ }^{3}$ and Comfort N.Akujobi ${ }^{3}$
}

\section{ABSTRACT}

\section{BACKGROUND}

The burden of tuberculosis (TB) and cardiovascular disease (CVD) is enormous worldwide. Public health programs have been challenged with the overlapping of TB and CVD epidemics.Mycobacterium tuberculosis (MTB) is also a main driver of atherogenesis, suggesting a potential pathogenic role of tuberculosis in cardiovascular disease. The objective of this study was to compare the serum levels of apolipoprotein B (apo B), apolipoprotein B48 (apo B48) and apolipoprotein B100 (apo $\mathrm{B} 100)$ between patients with tuberculosis and healthy subjects.

\section{METHODS}

A cross-sectional study was conducted involving 251 subjects consisting of 120 treatment naïve active TB patients [ $26 \mathrm{HIV}$ co infected (TB $+\mathrm{HIV}+$ ) and $82 \mathrm{~TB}+$ ), 12 malaria parasite co-infected ( $\mathrm{TB}+\mathrm{MP}+)], 26$ latent $\mathrm{TB}$ infected (LTB) and 105 healthy controls. Their body mass index (BMI) was calculated. Mycobacterium tuberculosis infection was determined by ZiehlNelseen (ZN) sputum smear microscopy and confirmed positive using GeneXpert. Latent TB was determined by Mantoux test, MP was evaluated by microscopy while HIV by immunochromatographic techniques using serial algorithm. Apolipoproteins were determined using spectrophotometry. A one-way ANOVA test and LSD's post hoc multiple comparisons were used for statistical analyses.

\section{RESULTS}

Significantly lower mean levels of BMI were observed in LTB, TB + , $\mathrm{TB}+\mathrm{HIV}+$ and $\mathrm{TB}+\mathrm{MP}+$ compared with the controls $(\mathrm{p}<0.005)$. The mean serum levels of apo B, apo B48 and B100 were significantly higher in LTB, $\mathrm{TB}+, \mathrm{HIV}+\mathrm{TB}+$ and $\mathrm{TB}+\mathrm{MP}+$ compared with apparently healthy controls $(\mathrm{p}<0.05)$.

\section{CONCLUSION}

Elevated levels of apolipoproteins among infected TB individuals might predispose them to cardiovascular disease.

Keywords: Apolipoprotein, atherosclerosis, tuberculosis patient, healthy subjects
${ }^{1}$ Chemical Pathology Unit, Department of Medical Laboratory Science, Faculty of Health Sciences and Technology, Nnamdi Azikiwe University, Nigeria

${ }^{2}$ Department of Human Biochemistry, Faculty of Basic Sciences, Nnamdi Azikiwe University, Nigeria ${ }^{3}$ Faculty of Medicine, Nnamdi Azikiwe University, Nigeria

\section{*Correspondence :}

Augustine C. Ihim, Ph.D.

Chemical Pathology Unit, Department of Medical Laboratory Science, Faculty of Health Sciences and Technology, Nnamdi Azikiwe University, P.M.B. 5025 Awka,

Anambra state, Nigeria

Email: ac.ihim@unizik.edu.ng Phone +2348035985883

ORCID ID: 0000-0001-9991-0714

Date of first submission, October 29 2020

Date of final revised submission, March 28, 2021

Date of acceptance, April 3, 2021

This open access article is distributed under a Creative Commons AttributionNon Commercial-Share Alike 4.0 International License

Cite this article as: Ihim AC, Meludu SC, Onyenekwe CC, Anyabolu AE, Akujobi CN. Serum apolipoprotein B increased among tuberculosis patients compared to healthy subjects. Univ Med 2021;40: 45-51. doi: 10.18051/UnivMed.2021. v40.45-51 


\section{INTRODUCTION}

Tuberculosis and cardiovascular disease (CVD) pose great public health challenges globally. The World Health Organization has been challenged with the increasing burden of tuberculosis and CVD epidemics. ${ }^{(1)}$ There is increasing evidence that many infections contribute to the pathogenesis of CVD including Mycobacterium tuberculosis. ${ }^{(2)}$ Some authors also revealed the association of latent tuberculosis with acute myocardial infarction (AMI). ${ }^{(2)}$ The potential mechanism for this association relied on a study that showed continuous activation of the immune system in latent and active tuberculosis. ${ }^{(3)}$ Antibodies to mycobacterial HSP65 cross-reacting with selfantigens in human blood vessels leading to autoimmunity may also have an effect on CVD risk. Monocytes/macrophages, lymphocytes and cytokines engaged in cell-mediated immune responses against Mycobacterium tuberculosis are also main drivers of atherogenesis, suggesting a potential pathogenic role of tuberculosis in CVD via mechanisms that have been described for other pathogens that establish chronic infection and latency. ${ }^{(3-5)}$

Consequently, apolipoprotein-B (apo B) containing lipoproteins are a suspected cause of atherosclerosis which is the main underlying cause of CVD. Apolipoprotein-B enters the wall of the arteries and can transport cholesterol into the arterial wall; if present in increased numbers, may be the main initiating factor in atherosclerosis. ${ }^{(6)}$ Apolipoprotein B100 (apo $\mathrm{B} 100)$ is the largest of the apoB group of proteins, consisting of 4563 amino acids. Apolipoprotein B100 is the apolipoprotein found in lipoproteins synthesized by the liver and is found in chylomicrons, very low-density lipoprotein cholesterol (VLDL-C), intermediatedensity lipoprotein cholesterol (IDL-C), lowdensity lipoprotein cholesterol (LDL-C) and lipoprotein(a) $[\mathrm{LP}(\mathrm{a})]$ particles. ${ }^{(7)}$ All these particles are atherogenic. ${ }^{(8)}$ Each of these particles contains a single apo B molecule.
Several studies have shown that apo B may be a better predictor of cardiovascular disease risk than LDL-C. ${ }^{(9,10)}$ Furthermore, it has been shown that apo B may be raised despite normal or low levels of LDL-C. Apolipoprotein-B also appears to predict on-treatment risk, when LDL$\mathrm{C}$ has been lowered by statin therapy. Similarly, a study by Ihim et al., ${ }^{(10)}$ on free fatty acid and lipid profile in active tuberculosis, latent tuberculosis, active TB and HIV, active TB and malaria parasite in subjects in Anambra concluded that low level of free fatty acid and hypolipidaemia in TB subjects could be attributed to tuberculosis. This observation is in line with the findings by Oyedeji et al. ${ }^{(11)}$ in their study on oxidative stress and lipid profile status in pulmonary tuberculosis patients in South Western Nigeria. The evaluation of apo B represents the total burden of the main lipoprotein particles involved in the atherosclerotic process. But another study showed different results, in that there was no significant difference in Apo B between patients with TB and healthy subjects. ${ }^{(12)}$

It has been shown that Mycobacterium tuberculosis obtains nutrients and metabolizes host derived lipids mainly fatty acids and cholesterol and uses them to cause and maintain disease. ${ }^{(13,14)}$ Despite evidence of hypolipidaemia among individuals with TB infection, ${ }^{(10)} \mathrm{CVD}$ is still on the increase among them. ${ }^{(1)}$ Consequently, this research objective was to compare the serum levels of apo B, apolipoprotein B48 (apo B48) and apo $\mathrm{B} 100$ between patients with tuberculosis and healthy subjects.

\section{METHODS}

\section{Research design}

This cross-sectional research was conducted at Nnamdi Azikiwe University Teaching Hospital (NAUTH), Nnewi, Anambra State, Nigeria, between May 2015 and January 2018 to compare the serum levels of apo B, apo B48 and apo B100 among individuals with MTB and apparently healthy controls. 


\section{Study population}

The study population consisted of 5518 suspected individuals with cardinal symptoms of tuberculosis who presented at Tuberculosis Directly Observed Therapy (TBDOT) clinics of Nnamdi Azikiwe University Teaching Hospital (NAUTH), Nnewi, between May, 2015 and January, 2018.

\section{Sampling technique}

Consecutive non-random sampling techniques was used to select individuals from the TB DOT centres before the initiation of therapy. Participants were individuals who met the inclusion criteria and consented after the purpose was explained to them and were recruited as they became available until the sample size was attained.

\section{Study subjects}

Sample size was calculated using $\mathrm{G}^{*}$ Power software version 3.0.10 (Universität Düsseldorf, Germany). Power analysis for one way ANOVA was conducted in $G^{*}$ Power to determine a sufficient sample size using an alpha of 0.05 , a power of 0.89 and a medium effect size. Based on these, the calculated total sample size of 245 has $89 \%$ power to detect a difference of 0.25 at a significance level of 0.05 . A total of 251 study subjects composed of 120 treatment naïve active TB patients $[26 \mathrm{HIV}$ co infected $(\mathrm{TB}+\mathrm{HIV}+$ ) and $82 \mathrm{~TB}+), 12$ malaria parasite co-infected $(\mathrm{TB}+\mathrm{MP}+)$ ], 26 latent TB infected (LTB) and 105 healthy controls (TB-HIV"TST") were recruited. At recruitment, all study subjects were interviewed using a standard questionnaire and demographic data were collected. The weight and height of all the subjects were measured and used to determine their body mass index (BMI). Mycobacterium tuberculosis infection was determined by Ziehl-Neelsen (ZN) sputum smear microscopy and confirmed positive using GeneXpert ${ }^{\circledR}$.

Newly diagnosed TB positive individuals with or without MP, and or HIV co -infections were recruited. The individuals above were those who did not receive any tuberculosis treatment before they were recruited (Category one, first line TB positive individuals), were between 1566 years old, and attending the TB DOTS Clinic, NAUTH, Nnewi, State Anambra.

Individuals infected with $\mathrm{TB}$ and on antiretroviral therapy were excluded. Patients diagnosed with pulmonary tuberculosis but having diabetes mellitus were also excluded from the study. Tobacco smokers, alcohol drinkers and participants who had other clinical problems such as diabetes and cardiovascular diseases were excluded from the study.

\section{Ethical consideration}

Ethical approval for the study was obtained from Nnamdi Azikiwe University Teaching Hospital Ethics Committee (NAUTHEC) under no. NAUTH/CS/66/VOL.7/79, Nnewi, Anambra State, Nigeria.

\section{Informed consent}

The aim, benefits and purpose of the study was explained to the individuals. Participation was voluntary and informed consent was obtained from all of the individuals. The individuals were allowed at any time they so desired to discontinue and that would not in any way affect their care. The information obtained from the individuals was kept highly confidential in observance of the privacy act.

\section{Sample collection \\ Sputum collection and processing}

Sputum samples were collected using the Directly Observed treatment short Course (DOTs) strategy specification and were processed using the Ziehl-Neelsen staining method and confirmed using the GeneXpert ${ }^{\circledR}$ by Cepheid.

\section{Blood sample collection}

Blood samples were collected once from individuals with active Mycobacterium tuberculosis infection. Firstly, immediately the individual was confirmed to be positive for pulmonary tuberculosis by Ziehl Neelsen's 
staining technique and GeneXpert MTB/RIF assay, before the initiation of anti-tuberculosis treatment (ATT). Blood samples were collected once from individuals with latent TB and from apparently healthy individuals (controls). Eight milliliters (8mls) of blood was collected from each individual at each period of blood collection, thick and thin blood films were made for microscopic detection of $P$. falciparum on recruitment and malaria Plasmodium falciparum/pan rapid test (Carestart ${ }^{\mathrm{TM}}$, Access Bio, USA) which is a chromatographic immunoassay for the qualitative detection of circulating $P$. falciparum antigen in whole blood was also used. Two milliliters $(2 \mathrm{ml})$ of blood was dispensed in ethylene diamine tetra acetic acid (EDTA) bottles and $6 \mathrm{ml}$ of blood was dispensed in plain tubes to separate serum for various biochemical assays. ${ }^{(15)}$ The blood in the plain tubes was allowed to stand for 30 minutes to clot and further centrifuged at $3500 \mathrm{rpm}$ for five minutes using Wisperfuge model 1384 centrifuge (Samson, Holland). Serum was separated from the clot with a micropipette into a sterile plain tube for the measurement of biochemical parameters. Each individual's blood sample was stored frozen at $-20^{\circ} \mathrm{C}$ in aliquots, in three cryovials to avoid repeated thawing and storing that would affect the result of the analysis.

\section{Diagnostic assessments}

The HIV status of the study subjects was determined using the Determine HIV-1/2 (Abbott Laboratories, Japan) as the screening test, the Capillus HIV-1/2 (Trinity Biotech, Ireland) as the confirmatory test and Uni-Gold HIV-1/2 recombinant (Trinity Biotech, Ireland) as a tie breaker test.

\section{Diagnosis of malaria}

P. falciparum malaria was detected using thick and thin blood smears for microscopic detection (employing Giemsa staining technique) and malaria plasmodium falciparum rapid test device (CARESTART ${ }^{\text {TM }}$ Malaria HRP2 (Pf) by ACCESS BIO,INC. USA).

\section{Mantoux test}

Tuberculin purified protein derivative (PPD) was utilized for the Mantoux test to assist in clinical diagnosis of tuberculosis for diagnosis and differential diagnosis of tuberculosis, early detection of tuberculosis and screening for infection by M. tuberculosis (latent tuberculosis infection). This test is known as the tuberculin skin test. The PPD used was obtained from BB - NCIPD Ltd, Sofia, Bulgaria. Each vial contained $1 \mathrm{ml}$ (10 doses) containing 50TU of PPD $=5 \mathrm{TU} / 0.1 \mathrm{ml}$ per dose ${ }^{(16)}$

\section{Estimation of Apo B, Apo B48, and Apo B100}

Apo B, Apo B48, and Apo B100 were estimated by sandwich enzyme immunoassay technique as described by Brodsky and Edward. ${ }^{(17)}$

\section{Statistical analysis}

The IBM Statistical Package for Social Sciences (SPSS) version 21 was used for the statistical analysis. ANOVA was used to determine if there were any statistical differences between the means of different groups of subjects. LSD's post hoc multiple comparisons were run to confirm where the differences occurred in the groups. The results were presented as mean \pm standard deviation. Significant levels were considered at $\mathrm{p}<0.05$.

\section{RESULTS}

Significantly lower mean levels of BMI were observed in individuals with LTB $(25.57 \pm 6.53$ $\left.\mathrm{kg} / \mathrm{m}^{2}\right)$, active TB $\left(24.11 \pm 3.84 \mathrm{~kg} / \mathrm{m}^{2}\right)$, human immunodeficiency and tuberculosis co-infection $\left(22.48 \pm 2.38 \mathrm{~kg} / \mathrm{m}^{2}\right)$ and tuberculosis and malaria parasite co-infection (TBMP) $(26.69 \pm 4.01 \mathrm{~kg} /$ $\left.\mathrm{m}^{2}\right)$ compared with the controls $(29.19 \pm 7.22$ $\left.\mathrm{kg} / \mathrm{m}^{2}\right)(\mathrm{p}<0.05)$.

The mean serum level of apolipoprotein B was significantly higher in individuals with active TB infection, TBHIV and TBMP co-infections $(2879.3 \pm 1.03 \mu \mathrm{g} / \mathrm{mL}, 2759.6 \pm 0.37 \mu \mathrm{g} / \mathrm{mL}$, and 
Table 1 Sociodemographic characteristics parameters of individuals with LTB, active TB infections, HIV\&TB, TB \& MP and apparently healthy controls (AHC)

\begin{tabular}{lcccccc}
\hline & $\begin{array}{c}\text { AHC } \\
(\mathbf{n}=\mathbf{1 0 5})\end{array}$ & $\begin{array}{c}\text { LTB } \\
(\mathbf{n}=\mathbf{2 6})\end{array}$ & $\begin{array}{c}\text { TB } \\
(\mathbf{n}=\mathbf{8 2})\end{array}$ & $\begin{array}{c}\text { TB HIV } \\
(\mathbf{n}=\mathbf{2 6})\end{array}$ & $\begin{array}{c}\text { TB MP } \\
(\mathbf{n}=\mathbf{1 2})\end{array}$ & p value \\
\hline Age $(\mathrm{yrs})$ & $35.61 \pm 9.60$ & $38.31 \pm 10.83$ & $36.44 \pm 14.20$ & $34.61 \pm 11.12$ & $39.33 \pm 7.43$ & 0.315 \\
BMI $\left(\mathrm{kg} / \mathrm{m}^{2}\right)$ & $29.19 \pm 7.22^{\mathrm{a}}$ & $25.57 \pm 6.53^{\mathrm{b}}$ & $24.11 \pm 3.84^{\mathrm{b}}$ & $22.48 \pm 2.38^{\mathrm{b}}$ & $24.21 \pm 3.85^{\mathrm{b}}$ & 0.001 \\
\hline
\end{tabular}

a-b Means in a row without a common superscript letter differ $(\mathrm{p}<0.05)$, as analyzed by one-way ANOVA. AHC: apparently healthy controls, LTB : latent tuberculosis; TBHIV: tuberculosis and HIV co-infection, TBMP: tuberculosis and malaria parasite co-infection. Results are expressed as mean $\pm \mathrm{SD}$ and are statistically significant at $\mathrm{p}<0.05$

$2656 \pm 0.462 \mu \mathrm{g} / \mathrm{mL}$ ) respectively compared with LTBI $(2493.7 \pm 0.83 \mu \mathrm{g} / \mathrm{mL})$ and apparently healthy controls $(2033.2 \pm 1.10 \mu \mathrm{g} / \mathrm{mL})(\mathrm{p}<0.05)$. Furthermore, the mean serum level of apolipoprotein $\mathrm{B} 48$ in individuals with active TB infection, TBHIV and TBMP co-infections (364.4 $\pm 8.5 \mu \mathrm{g} / \mathrm{mL}, 358.7 \pm 1.98 \mu \mathrm{g} / \mathrm{mL}$ and $386.4 \pm$ $2.36 \mu \mathrm{g} / \mathrm{mL}$, respectively) is significantly higher than in individuals with LTB $(106.3 \pm 1.10 \mu \mathrm{g} /$ $\mathrm{mL})$ and apparently healthy controls $(100.2 \pm 5.50$ $\mu \mathrm{g} / \mathrm{mL})(\mathrm{p}<0.05)$. The mean serum level of apolipoprotein B $100(\mu \mathrm{g} / \mathrm{mL})$ was significantly higher in individuals with LTB, active TB infection, TBHIV and TBMP $(2489.4 \pm 0.84,2879.5 \pm 1.03$, $3448.3 \pm 0.22$ and $2880.8 \pm 0.46$, respectively) than in apparently healthy controls $(2032.3 \pm$ $1.11)(\mathrm{p}<0.05)$.

\section{DISCUSSION}

BMI has been used as an indicator of malnutrition ${ }^{(18)}$ or total adiposity, ${ }^{(19)}$ although with many limitations. However, the mean BMI values of the entire study group were within the normal reference range. The lower mean levels of BMI observed in the test groups might be the result of depletion in body lipids and free fatty acids associated with Mycobacterium tuberculosis infection. ${ }^{(10)}$ These lower mean levels of BMI observed in the test groups are in agreement with the studies by Yen et al. ${ }^{(20)}$ and Casha and Scarci. ${ }^{(21)}$ The significantly higher mean serum levels of apo B, B48 and B100 in Mycobacterium tuberculosis infected individuals in this study could be attributed to Mycobacterium tuberculosis infection. Several studies have shown that apo B may be a better predictor of cardiovascular disease risk than LDL-C. ${ }^{(6,9,12)}$ Apolipoprotein B is an important component of most atherogenic lipoprotein particles. ${ }^{(11)}$ The apolipoproteins were higher in the active TB and co-morbidity groups than in the controls. Apolipoprotein B containing lipoproteins are the ones that are most likely to enter the wall of the arteries. They are capable of trafficking cholesterol into the artery

Table 2. Serum levels of apolipoprotein B, apolipoprotein B48 and B100 among healthy controls, LTB, active TB, TBHIV and TBMP individuals

\begin{tabular}{lcccccc}
\hline & $\begin{array}{c}\text { AHC } \\
(\mathbf{n}=\mathbf{1 0 5})\end{array}$ & $\begin{array}{c}\text { LTB } \\
(\mathbf{n = 2 6})\end{array}$ & $\begin{array}{c}\text { TB } \\
(\mathbf{n = 8 2})\end{array}$ & $\begin{array}{c}\text { TB HIV } \\
(\mathbf{n = 2 6})\end{array}$ & $\begin{array}{c}\text { TB MP } \\
(\mathbf{1 2})\end{array}$ & $\begin{array}{c}\mathbf{p} \\
\text { value }\end{array}$ \\
\hline $\begin{array}{l}\text { Apo B } \\
(\mu \mathrm{g} / \mathrm{mL})\end{array}$ & $2033.2 \pm 1.10^{\mathrm{a}}$ & $2493.7 \pm 0.83^{\mathrm{b}}$ & $2879.3 \pm 1.03^{\mathrm{c}}$ & $2759.6 \pm 0.37^{\mathrm{c}}$ & $2656 \pm 0.462^{\mathrm{c}}$ & $<0.001$ \\
$\begin{array}{l}\mathrm{Apo} \mathrm{B} \mathrm{48} \\
(\mu \mathrm{g} / \mathrm{mL})\end{array}$ & $100.2 \pm 5.50^{\mathrm{a}}$ & $106.3 \pm 1.10^{\mathrm{a}}$ & $364.4 \pm 8.5^{\mathrm{b}}$ & $358.7 \pm 1.98^{\mathrm{b}}$ & $386.4 \pm 2.36^{\mathrm{b}}$ & $<0.001$ \\
& & & & & & \\
$\mathrm{Apo} \mathrm{B} \mathrm{100}$ & $2032.3 \pm 1.11^{\mathrm{a}}$ & $2489.4 \pm 0.84^{\mathrm{b}}$ & $2879.5 \pm 1.03^{\mathrm{c}}$ & $3448.3 \pm 0.22^{\mathrm{c}}$ & $2880.8 \pm 0.46^{\mathrm{c}}$ & $<0.001$ \\
\hline$\mu \mathrm{gL})$ & & & & & & \\
\hline
\end{tabular}

a-b-c Means in a row without a common superscript letter differ $(\mathrm{p}<0.05)$, as analyzed by one-way ANOVA AHC: apparently healthy controls, LTB : latent tuberculosis, TB+HIV+: tuberculosis and HIV co-infection, TB+MP+: tuberculosis and malaria parasite co-infection. Results are expressed as mean $\pm \mathrm{SD}$ and are statistically significant at $\mathrm{p}<0.05$ 
wall, and if present in increased numbers they may be the main initiating factor in atherosclerosis. Retention of apo B containing lipoprotein particles within the arterial wall is an essential part of the process. The measurements of apo B represent the total burden of the main lipoprotein particles involved in the atherosclerotic process. ${ }^{(9)}$ Apolipoprotein B occurs in two main forms, apoB48 and apoB100. ApoB48 is synthesized mainly by the small intestine. ${ }^{(9,12)}$ and is primarily found in chylomicrons. ${ }^{(13)}$ Apo B100 is the largest of the apo $B$ group of proteins, consisting of 4563 amino acids. Apolipoprotein B100 is the apo-lipoprotein found in lipoproteins synthesized by the liver and it is found in chylomicrons, VLDL, IDL, LDL and LP (a) particles. ${ }^{(7)}$ All these particles are atherogenic. Each of these particles contains a single apo B molecule. Therefore, from the viewpoint of atherosclerosis and cardiovascular risk, apoB100 is the important one. ${ }^{(8,18,19)}$

Furthermore, the mean serum levels of apo lipoprotein B, apo lipoprotein B48 and B100 were significantly higher in individuals with TBHIV and TBMP co- infections. Hence, they might be at a higher risk of predisposition to cardiovascular disease..$^{(9,12)}$ This finding is in line with previous studies, ${ }^{(8,20)}$ and confirmed that high levels of apo B are indicative of a higher risk to cardiovascular disease in tuberculosis and concluded that concentrations of apo B are superior indicators of vascular/heart disease and CVD risk prediction than standard lipid profile. Lack of prior awareness of the participants, on the importance of research was a major constraint in carrying out this study. Monitoring serum apolipoprotein B levels may help reduce the occurrence of cardiovascular disease in patients with tuberculosis. Further research is necessary using a longitudinal follow up design to assess the effect of Mycobacterium tuberculosis (MTB) infection on serum levels of apo B, apo B48, apo B100, atherogenic index and coronary risk index in individuals with MTB infection before, during and after treatment.

\section{CONCLUSION}

It was observed in this research that higher mean serum levels of apo B, apo B48 and apo $\mathrm{B} 100$ in tuberculosis patients might predispose them to cardiovascular disease.

\section{CONFLICTS OF INTEREST}

The authors declare that they have no conflicts of interest.

\section{CONTRIBUTORS}

$\mathrm{ACI}$ and SCM conceived and designed the research proposal. CCO and AEA performed sample collection, experiments and data analysis. $\mathrm{ACI}$ and CNA contributed to the final version of the manuscript. All authors have read and approved the final manuscript.

\section{ACKNOWLEDGEMENTS}

The authors would like to pay their most profound gratitude to the Tertiary Education Trust Fund (TETFUND), Nigeria for the research grants extended for the accomplishment of this research activity. The management and staff of Nnamdi Azikiwe University Teaching Hospital, Nnewi, and Reene Medical Diagnostic Laboratory, Awada, Anambra State, for the laboratory analyses of all biochemical parameters, staff of TBDOT laboratory NAUTH Nnewi, Anambra State.

\section{REFERENCES}

1. Huaman MA, Henson D, Ticona E, Sterling TR, Garvy BA. Tuberculosis and cardiovascular disease: linking the epidemics. Trop Dis Travel Med Vaccines 2015;1:10. doi: 10.1186/s40794-0150014-5.

2. Huaman MA, Eduardo T, Gustavo M, et al. The relationship between latent tuberculosis infection and acute myocardial infarction. Clin Infect Dis 2018;66:886-92. doi: 10.1093/cid/cix910. 
3. Sullivan ZA, Wong EB, Ndung'u T, Kasprowicz VO, Bishai WR. Latent and active tuberculosis infection increase immune activation in individuals co-infected with HIV. EBioMed 2015; 2;334 40. doi: 10.1016/j.ebiom.2015.03.005.

4. Cowan J, Pandey S, Filion LG, Angel JB, Kumar A, Cameron DW. Comparison of interferon-ã-, interleukin (IL)-17- and IL-22-expressing CD4 T cells, IL-22-expressing granulocytes and proinflammatory cytokines during latent and active tuberculosis infection. Clin Exp Immunol 2012;167:317-29. doi: 10.1111/j.1365-2249.2011. 04520.x.

5. Huaman MA, Deepe GS Jr, Fichtenbaum CJ. Elevated circulating concentrations of interferongamma in latent tuberculosis infection. Pathog Immun 2016; 1:291-303. doi:10.20411/.v1i2.149.

6. Paramjit KS, Salma MA, Musaad ATR, et al. Lipoprotein biomarkers and risk of cardiovascular disease, a laboratory medicine best practices systematic review. J Appl Lab Med 2016;1:214-9. doi: 10.1373/jalm.2016.021006.

7. Devaraj S, Semaan JR, Jialal I. Biochemistry, apolipoprotein B. Treasure Island (FL): StatPearls Publishing LLC;2021.

8. Frayn K, Bernard S, Spalding K, Arner P. Adipocyte triglyceride turnover is independently associated with atherogenic dyslipidemia. J Am Heart Assoc 2012;1:e003467. doi: 10.1161/ JAHA.112.003467.

9. Sniderman AD, Islam S, McQueen M, et al. Age and cardiovascular risk attributable to apolipoprotein B, low density lipoprotein cholesterol or non high density lipoprotein cholesterol. J Am Heart Assoc 2016;5. doi.org/ 10.1161/JAHA.116.003665.

10. Ihim AC, Obi PC, Meludu SC, Onyenekwe CC, Anyabolu EA, Njoku CMA. Free fatty acid and lipid profile in active $\mathrm{Tb}$, latent $\mathrm{Tb}$, active $\mathrm{Tb}$ And Hiv, active $\mathrm{Tb}$ and malaria parasite in subjects in Anambra. Eur J Biomed Pharm 2018;5:506-1.

11. Oyedeji SO, Oguntuase NR, Esan A, Adesina AA, Oke OT. Oxidative stress and lipid profile status in pulmonary tuberculosis patients in South Western Nigeria. Greener J Med Sci 2013;3:228 32.
12. Jiang TT, Shi LY, Wei LL, et al. Serum amyloid A, protein $\mathrm{Z}$, and $\mathrm{C} 4 \mathrm{~b}$-binding protein â chain as new potential biomarkers for pulmonary tuberculosis. PLoS ONE2017;12:e0173304. doi: 10.1371/journal.pone.0173304.

13. Kaley MW, Rachael AF, Brian CV. Cholesterol and fatty acids grease the wheels of Mycobacterium tuberculosis pathogenesis. Pathog Dis 2018;76:114. doi: $10.1093 /$ femspd/fty021

14. Rahul KM, Suman B, Manju YK. Triacylglycerols: fuelling the hibernating Mycobacterium tuberculosis. Front Cell Infect Microbiol 2019; 8:1-8. doi: 10.3389/fcimb.2018.00450.

15. AkiibinuA, Mabekoje O, Akinola F, et al. Cellular activation and antioxidants depletion in pulmonary tuberculosis patients. EC Microbiol 2019;15:210-16.

16. Cheesbrough M. Protein. In: District laboratory practice in tropical countries, 2nd ed. Part 1. United Kingdom: Cambridge University Press;2007.p. 310-4. doi.org/10.1017/CBO9780511581304.

17. Brodsky JL, Fisher EA. The many intersecting pathways underlying apolipoprotein B secretion and degradation. Trends Endocrinol Metab 2008; 19:254-9. doi: 10.1016/j.tem.2008.07.002.

18. Gebremedhin G, Yemane A, Feyissa C, et al. Lipid profile in tuberculosis patients with and without human immunodeficiency virus infection. Int J Chronic Dis 2017; Article ID: 3843291. https:// doi.org/10.1155/2017/3843291.

19. Pusapati MR, Girijasankar G, Ramesh BP. Association of lipid profile, atherogenic indices, and LPL Hind-III gene polymorphism with coronary artery disease positive subjects. Int $\mathrm{J}$ Pharm Clin 2017;91:6-15. doi.org/10.25258/ ijpcr.v9i1.8257.

20. Yen YF, Chuang PH, Yen MY, et al. Association of body mass index with tuberculosis mortality: a population-based follow-up study. Medicine (Baltimore) 2016;95:e2300. doi: 10.1097/ MD.0000000000002300.

21. Casha AR, Scarci M. The link between tuberculosis and body mass index. J Thorac Dis 2017;9:E301-E303. doi: 10.21037/jtd.2017.03.47. 